\title{
Fuzzy play, matching devices and coordination failures
}

Citation for published version (APA):

Herings, P. J. J., Mauleon, A., \& Vannetelbosch, V. (2001). Fuzzy play, matching devices and coordination failures. METEOR, Maastricht University School of Business and Economics. METEOR Research Memorandum No. 020 https://doi.org/10.26481/umamet.2001020

Document status and date:

Published: 01/01/2001

DOI:

10.26481/umamet.2001020

Document Version:

Publisher's PDF, also known as Version of record

\section{Please check the document version of this publication:}

- A submitted manuscript is the version of the article upon submission and before peer-review. There can be important differences between the submitted version and the official published version of record.

People interested in the research are advised to contact the author for the final version of the publication, or visit the DOI to the publisher's website.

- The final author version and the galley proof are versions of the publication after peer review.

- The final published version features the final layout of the paper including the volume, issue and page numbers.

Link to publication

\footnotetext{
General rights rights.

- You may freely distribute the URL identifying the publication in the public portal. please follow below link for the End User Agreement:

www.umlib.nl/taverne-license

Take down policy

If you believe that this document breaches copyright please contact us at:

repository@maastrichtuniversity.nl

providing details and we will investigate your claim.
}

Copyright and moral rights for the publications made accessible in the public portal are retained by the authors and/or other copyright owners and it is a condition of accessing publications that users recognise and abide by the legal requirements associated with these

- Users may download and print one copy of any publication from the public portal for the purpose of private study or research.

- You may not further distribute the material or use it for any profit-making activity or commercial gain

If the publication is distributed under the terms of Article $25 \mathrm{fa}$ of the Dutch Copyright Act, indicated by the "Taverne" license above, 


\title{
Fuzzy Play, Matching Devices and Coordination Failures*
}

\author{
P. Jean-Jacques Herings \\ Department of Economics \\ Ana Mauleon \\ Universiteit Maastricht \\ IRES \\ Université Catholique de Louvain \\ Vincent Vannetelbosch ${ }^{\dagger}$ \\ FNRS and IRES \\ Université Catholique de Louvain
}

November 2001

\begin{abstract}
We revisit $n$-player coordination games with Pareto-ranked Nash equilibria. The novelty is that we introduce fuzzy play and a matching device, where each player does not choose which pure strategy to play, but instead chooses a nonempty subset of his strategy set that he submits to the matching device. The matching device is a very simple one. It only selects a match if possible, and it selects randomly some strategy belonging to the strategy set sent by each player otherwise. That is, it does not impose that the best alternatives are matched. Using the concepts of perfect Nash equilibrium and of trembling-hand perfect rationalizability, we show that players coordinate directly on the Pareto optimal outcome. This implies that they neither use the option of fuzzy play, nor make use of the matching device.
\end{abstract}

JEL Classification Codes: C72, C78, D61

Keywords: Coordination Games, Coordination Failures, Rationalizability, Matching Devices.

${ }^{*}$ Vincent Vannetelbosch is Chargé de Recherches at the Fonds National de la Recherche Scientifique. The research of Ana Mauleon has been made possible by a fellowship of the Spanish government. Financial support from the Belgian French Community's program Action de Recherches Concertée 99/04-235 (IRES, Université catholique de Louvain) is gratefully acknowledged.

${ }^{\dagger}$ Corresponding author address : IRES, Université Catholique de Louvain, 3 Place Montesquieu, B1348 Louvain-la-Neuve, Belgium. E-mail: vannetelbosch@ires.ucl.ac.be, Tel: 0032-10-474142, Fax: $0032-$ 10-473945. 


\section{Introduction}

There is a widespread interest in coordination games with multiple Pareto-ranked equilibria, since these games have many equilibria that are bad for all concerned, but still are difficult to rule out by standard notions of rationality. The coordination game is of particular importance for macroeconomists, who believe that an economy may be become mired in a low-output equilibrium, see e.g. Bryant [2], Cooper [4], and Cooper and John [6]. Indeed, while all agents in the economy understand that the outcome is inefficient, each agent, acting indepently, is powerless to coordinate the activities of other agents to reach a Pareto-preferred equilibrium. So, from this perspective, a depression in aggregate economic activity arises when the economy falls into the trap of a low activity level Nash equilibrium.

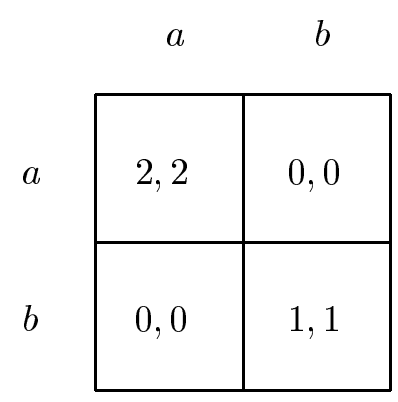

Figure 1: A $2 \times 2$ coordination game

Consider a $2 \times 2$ coordination game between two players. The payoff matrix is given in Figure 1. There are two pure strategy Nash equilibria in this simultaneous move game, the strategy profiles $(a, a)$ and $(b, b)$, as well as a mixed strategy equilibrium in which each player selects the action $a$ with probability $\frac{1}{3}$. These are Nash equilibria because each player is acting optimally given the choice of the other. The equilibria of this coordination game are strict Nash equilibria. Consequently, the strategy profile $(b, b)$ also satisfies the conditions imposed by the most refined equilibrium notions such as strategic stability in the sense of Kohlberg and Mertens [12]. The multiplicity of equilibria, and thus the possibility of a Pareto-inferior equilibrium, derives from players' inability to coordinate their choices in this strategic environment. As a consequence, realized equilibrium outcomes that are Pareto-suboptimal relative to other equilibria are often termed coordination failures.

One conclusion of a fair amount of experimental evidence is that coordination problems are not a pure theoretical curiosity. In particular, coordination failures are routinely 
observed in experimental games, see e.g. Cooper et al. [5], and Ochs [13].

Complementary to the accumulation of evidence on coordination games has been the development of theories concerning equilibrium selection in these games. Harsanyi and Selten [9] have proposed the risk dominance principle. This principle models that the play of certain equilibrium strategies is riskier than the play of others given the underlying strategic uncertainty of a game. Carlsson and van Damme [3] have provided an argument for selection of an equilibrium in a coordination game. Their idea is to explore the equilibria of a nearby game of incomplete information. The equilibrium for the coordination game is then the limit of the equilibrium for the nearby game as the amount of incomplete information goes to zero. They find that in the limit it is the risk-dominant equilibrium that is selected. Another approach to equilibrium selection involves exploring the dynamics of coordination games. This approach requires the specification of a dynamic process describing the play of agents involved in such a game, see e.g. Kandori et al. [11]. Another part of the literature has looked for possible remedies to coordination problems like preplay communication or cheap talk (see Farrel [7], [8] and Rabin [15]).

This paper considers a novel and simple way to resolve coordination problems, which consists of the combination of fuzzy play and the introduction of a matching device. By fuzzy play we mean that each player does not choose which pure strategy to play, but instead chooses a nonempty subset of his strategy set that he submits to a matching device. The matching device is a very simple one. It only selects a match if possible, and it selects randomly some strategy belonging to the strategy set sent by each player otherwise. That is, it does not impose that the best alternatives are matched. We focus on pure $n$-player coordination games with Pareto-ranked Nash equilibria.

For the $2 \times 2$ coordination game represented in Figure 1, players now have to choose between sending to the matching device either only the action $a$, or only the action $b$, or both actions $a$ and $b$. The matching device selects a match if possible, it selects randomly some strategy belonging to the strategy set sent by each player otherwise. That is, if both players send both actions $a$ and $b$ to the device, then the pair $(a, a)$ is selected with probability $\pi \in(0,1)$ and the pair $(b, b)$ is selected with probability $1-\pi$. If one player sends only the action $a$, while the other player sends both actions $a$ and $b$, then the device selects the pair $(a, a)$ with probability one; and so on. Payoffs of this new game are given in Figure 2 with $x=1+\pi$.

Using the concepts of perfect Nash equilibrium and of trembling-hand perfect rationalizability, we show that players coordinate directly on the best match possible. They do not use the option of fuzzy play, but submit a single strategy to the matching device. This strategy is the one corresponding to the Pareto optimal outcome. 


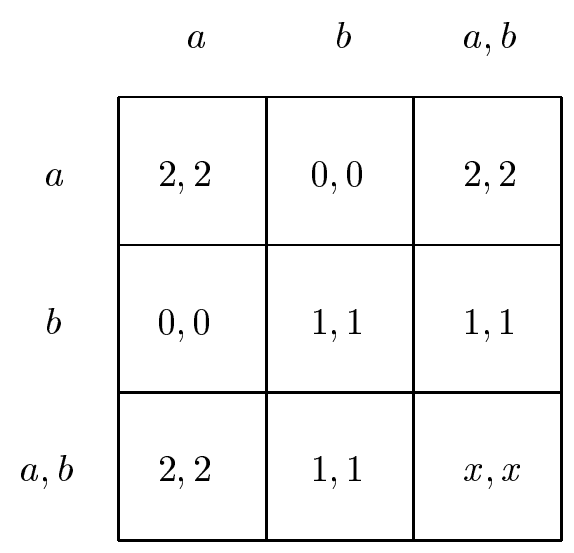

Figure 2: Fuzzy play in the $2 \times 2$ coordination game

The concept of trembling-hand perfect rationalizability reverts to the iterative elimination of weakly dominated strategies for the class of two-player normal-form games. Let us apply this well-known concept to our example. Obviously, the strategy which consists of sending only the action $b$ to the device is weakly dominated by the strategy where both actions $a$ and $b$ are sent. At the first round of the iterative procedure we eliminate the strategy which consists of sending only the action $b$. At the second round, the strategy where both actions are sent is now weakly dominated by the strategy which consists of sending only the action $a$. So, the unique trembling-hand perfect rationalizable solution is the one where both players choose to send only the Pareto-optimal action $a$.

\section{$2 \quad$ Fuzzy play and the matching device}

We consider an $n$-player pure coordination game denoted by $G=\left\langle N,\left\{A^{i}\right\}_{i \in N},\left\{u^{i}\right\}_{i \in N}\right\rangle$, where $N=\{1, \ldots, n\}$ is the set of players, $A^{i}$ is the finite set of actions or pure strategies of player $i$, and $u^{i}$ is player $i$ 's payoff function. A game is a coordination game if the players have the same number $m$ of strategies, which are indexed so that it is always a strict Nash equilibrium for both players to play strategies having the same index. Without loss of generality, we may assume that the sets of pure strategies of all players coincide, $A^{1}=\cdots=A^{n}$, which makes it meaningful to take intersections of such sets.

A pure coordination game is a coordination game for which the payoffs off the diagonal are zero. In the game $G$ we have that strict Nash equilibria are on the diagonal, and outside the diagonal the payoffs are zero for both players. Finally, we impose that the strict Nash equilibria are Pareto ranked, without loss of generality decreasing in the index of the 
strategy. Summarizing,

$$
\begin{array}{ll}
u^{i}\left(a_{1}^{1}, \ldots, a_{1}^{n}\right)>\cdots>u^{i}\left(a_{m}^{1}, \ldots, a_{m}^{n}\right)>0, & i \in N, \\
u^{i}\left(a_{k^{1}}^{1}, \ldots, a_{k^{n}}^{n}\right)=0, & k^{i^{\prime}} \neq k^{i^{\prime \prime}} \text { for some } i^{\prime}, i^{\prime \prime} \in N .
\end{array}
$$

We introduce both fuzzy play and a matching device. By fuzzy play we mean that a player does not necessarily restrict himself to play a single pure strategy $a_{k}^{i}$, but instead chooses a nonempty subset of his strategy set $A^{i}$ that he submits to the matching device. He thereby rules out that strategies outside $A^{i}$ are played. As a consequence, the set of strategies of each player becomes

$$
S^{i}=\left\{s^{i} \mid \emptyset \neq s^{i} \subseteq A^{i}\right\}, i \in N
$$

The matching device is assumed to operate as follows. It randomly selects a match if possible, and it selects randomly some strategy belonging to the strategy set sent by each player otherwise. That is, the matching device does not impose that the best alternatives are matched.

Let $\pi\left(a_{k}^{i}\right)$ denote the prior probability that the matching device selects the strategy $a_{k}^{i} \in A^{i}, i \in N$. It is assumed that $\pi\left(a_{k}^{i}\right)>0$ for all $k, \sum_{a_{k}^{i} \in A^{i}} \pi\left(a_{k}^{i}\right)=1$, and $\pi\left(a_{k}^{1}\right)=$ $\cdots=\pi\left(a_{k}^{n}\right)=\pi_{k}, k=1, \ldots, m$.

Suppose player $i$ submits the set of actions $s^{i} \in S^{i}$ to the matching device. Two cases have to be distinguished. Either the players' action sets have one or more actions in common, or they have nothing in common. That is, either there is $k$ such that for all $i \in N, a_{k}^{i} \in s^{i}$, or there is no $k$ such that for all $i \in N, a_{k}^{i} \in s^{i}$, so $\cap_{i \in N} s^{i}=\emptyset$. If $\cap_{i \in N} s^{i}=\emptyset$, then $a_{k}^{i} \in s^{i}$ is chosen with probability

$$
\frac{\pi_{k}}{\sum_{a_{l}^{i} \in s^{i}} \pi_{l}}, \quad i \in N
$$

If $\cap_{i \in N} s^{i} \neq \emptyset$ and $a_{k} \in \cap_{i \in N} s^{i}$, then $a_{k}$ is chosen with probability

$$
\frac{\pi_{k}}{\sum_{a_{l} \in \cap_{i \in N} s^{i}} \pi_{l}}
$$

The way the matching device selects strategies is assumed to be common knowledge among all players.

We can express the payoffs of the induced game as follows:

$$
U^{i}\left(s^{1}, \ldots, s^{n}\right)= \begin{cases}0 & \text { if } \cap_{i \in N} s^{i}=\emptyset \\ \frac{\sum_{a_{k} \in \cap_{i \in N} s^{i}} \pi_{k} \cdot u^{i}\left(a_{k}^{1}, \ldots, a_{k}^{n}\right)}{\sum_{a_{k} \in \cap_{i \in N} s^{i}} \pi_{k}} & \text { otherwise. }\end{cases}
$$

We denote the induced game by $\mathcal{G}=\left\langle N,\left\{S^{i}\right\}_{i \in N},\left\{U^{i}\right\}_{i \in N}\right\rangle$. The concepts we will use to analyze $\mathcal{G}$ are perfect Nash equilibrium and trembling-hand perfect rationalizability. 


\section{Perfect Nash equilibrium}

Three equivalent definitions of perfect Nash equilibrium have been proposed in the literature. One of them has been introduced by Selten [16] and is the following. A perfect Nash equilibrium is a limit point of a sequence of completely mixed strategy profiles with the property that it is a best reply against every element in the sequence. As general notation, we denote by $\Delta(X)$ the set of all Borel probability measures on $X$. For finite $X$, we denote by $\Delta^{0}(X)$ the set of all Borel probability measures giving positive probability to each member of $X$. Given $c^{i} \in \Delta\left(S^{i}\right)$, we denote by $c^{i}\left(s^{i}\right)$ the probability that $c^{i}$ assigns to the subset of pure strategies $s^{i}$. Perfect Nash equilibrium for the game $\mathcal{G}$ is defined formally as follows.

Definition 1 A perfect Nash equilibrium of the game $\mathcal{G}$ is a mixed strategy profile $c \in$ $\prod_{i \in N} \Delta\left(S^{i}\right)$ with the property that there exists a sequence $\left(c_{n}\right)_{n=0}^{\infty}$ of completely mixed strategy profiles that converges to $c$ such that for each player $i$ the strategy $c^{i}$ is a best response to $c_{n}^{-i}$ for all values of $n$.

We say that a player's strategy is weakly dominated if the player has another strategy at least as good no matter what the other players do and better for at least some strategy profile of the other players. To characterize the perfect Nash equilibria of the game $\mathcal{G}$, the following two lemmas are very useful.

Lemma 1 If a strategy profile is a perfect Nash equilibrium of $\mathcal{G}$, then the strategy of neither player is weakly dominated.

Lemma 2 The game $\mathcal{G}$ possesses at least one trembling hand perfect equilibrium.

The proofs of Lemma 1 and Lemma 2 can be found in van Damme [17, p.49] and in Selten [16, p.48], respectively. Before characterizing the perfect Nash equilibria, we first examine the set of all Nash equilibria of the game $\mathcal{G}$.

Theorem 1 The strategy profile $s=\left(s^{1}, \ldots, s^{n}\right) \in S$ is a pure Nash equilibrium of $\mathcal{G}$ if and only if for all $i \in N, u^{i}\left(a_{k^{*}}^{1}, \ldots, a_{k^{*}}^{n}\right) \leq U^{i}(s)$, where $k^{*}=\min \left\{k \mid a_{k} \in \cap_{j \in N \backslash\{i\}} s^{j}\right\}$ and $u^{i}\left(a_{k^{*}}\right)=0$ if $\cap_{j \in N \backslash\{i\}} s^{j}=\emptyset$.

Proof. Consider a strategy profile $s \in S$. Player $i$ does not deviate if and only if for all $a_{k} \in \cap_{j \in N \backslash\{i\}} s^{j}$ it holds that $u^{i}\left(a_{k}^{1}, \ldots, a_{k}^{n}\right) \leq U^{i}(s)$. This observation leads immediately to the result. 
From Theorem 1 we derive that the Nash equilibria in symmetric pure strategies of the game $\mathcal{G}$ coincide with the Nash equilibria in pure strategies of the game $G$. Symmetry implies $s^{1}=\cdots=s^{n}$. Next, from our characterization of pure strategy Nash equilibria of $\mathcal{G}$ one may immediately infer that $s^{i}, i \in N$, is a singleton. Moreover, each strategy combination $\left(\left\{a_{k}^{1}\right\}, \ldots,\left\{a_{k}^{n}\right\}\right)$ is a Nash equilibrium of $\mathcal{G}$. Obviously, each strategy combination $\left(a_{k}^{1}, \ldots, a_{k}^{n}\right)$ is a Nash equilibrium of $G$. We have shown the following result.

Corollary 1 The symmetric pure strategy Nash equilibria of the game $\mathcal{G}$ are $\left(\left\{a_{k}\right\}, \ldots,\left\{a_{k}\right\}\right)$, $k=1, . ., m$, and coincide with the pure strategy Nash equilibria of the game G, given by $\left(a_{k}, \ldots, a_{k}\right), k=1, . ., m$.

We turn next to the characterization of perfect Nash equilibria.

Theorem 2 If the strategy profile $\left(s^{1}, \ldots, s^{n}\right)$ is a perfect Nash equilibrium of $\mathcal{G}$, then $\cap_{i \in N} s^{i}=\left\{a_{1}\right\}$.

Proof. Consider any $s^{i}$ such that $a_{1}^{i} \notin s^{i}$. We show that $s^{i}$ is weakly dominated by $s^{i} \cup\left\{a_{1}^{i}\right\}$. First, against $s^{-i}$ such that $a_{1} \in \cap_{j \in N \backslash\{i\}} s^{j}$, we have

$$
\begin{aligned}
U^{i}\left(s^{i} \cup\left\{a_{1}^{i}\right\}, s^{-i}\right)= & \sum_{a_{k} \in \cap_{j \in N} s^{j}} \frac{\pi_{k}}{\pi_{1}+\sum_{a_{l} \in \cap_{j \in N} s^{j}} \pi_{l}} \cdot u^{i}\left(a_{k}^{1}, \ldots, a_{k}^{n}\right)+ \\
& \frac{\pi_{1}}{\pi_{1}+\sum_{a_{l} \in \cap_{j \in N} s^{j}} \pi_{l}} \cdot u^{i}\left(a_{1}^{1}, \ldots, a_{1}^{n}\right) \\
> & \sum_{a_{k} \in \cap_{j \in N^{j}}} \frac{\pi_{k}}{\sum_{a_{l} \in \cap_{j \in N} s^{j}} \pi_{l}} \cdot u^{i}\left(a_{k}^{1}, \ldots, a_{k}^{n}\right) \\
= & U^{i}\left(s^{i}, s^{-i}\right) .
\end{aligned}
$$

Second, against $s^{-i}$ such that $a_{1} \notin \cap_{j \in N \backslash\{i\}} s^{j}$, we have

$$
U^{i}\left(s^{i} \cup\left\{a_{1}^{i}\right\}, s^{-i}\right)=U^{i}\left(s^{i}, s^{-i}\right)=\sum_{a_{k} \in \cap_{j \in N} s^{j}} \frac{\pi_{k}}{\sum_{a_{l} \in \cap_{j \in N} s^{j}} \pi_{l}} \cdot u^{i}\left(a_{k}^{1}, \ldots, a_{k}^{n}\right) .
$$

Using Lemma 1 and knowing that every strategy $s^{i}$ which does not contain $a_{1}^{i}$ is weakly dominated by $s^{i} \cup\left\{a_{1}^{i}\right\}$, it follows that no perfect Nash equilibrium puts positive weight on such a strategy $s^{i}$. Using our characterization of Nash equilibria in Theorem 1 , it follows that the strategy $\left(s^{1}, \ldots, s^{n}\right) \in S$ is a perfect Nash equilibrium only if $\cap_{i \in N} s^{i}=\left\{a_{1}\right\}$.

Corollary 2 The unique symmetric perfect Nash equilibrium of $\mathcal{G}$ is $\left(\left\{a_{1}^{1}\right\}, \ldots,\left\{a_{1}^{n}\right\}\right)$. 


\section{Trembling-hand perfect rationalizability}

In the same way as rationalizability (Bernheim [1], Pearce [14]) is related to Nash equilibrium, the concept of trembling-hand perfect rationalizability due to Herings and Vannetelbosch [10] is related to perfect Nash equilibrium. Instead of using best responses as in rationalizability, the players are required to use cautious best responses in trembling-hand perfect rationalizability.

Another motivation which leads to the trembling-hand perfect rationalizability concept is obtained by carrying the logic behind cautious rationalizability (due to Pearce [14]) one step further. This implies that one wants to consider a solution concept where players eliminate responses that are not cautious in each round. All pure strategies that haven't been deleted yet are considered as possible by the players, and therefore they do not use conjectures that put probability zero on some of these strategies. Trembling-hand perfect rationalizability (THPR) is defined by the following iterative procedure.

Definition 2 Let $T_{0}=\prod_{i \in N} \Delta\left(S^{i}\right)$. For $k \geq 1, T_{k}=\prod_{i \in N} T_{k}^{i}$ is inductively defined as follows: $c^{i}$ belongs to $T_{k}^{i}$ if $c^{i} \in T_{k-1}^{i}$ and there is $c^{-i} \in \operatorname{int}\left(\operatorname{ch}\left(T_{k-1}^{-i}\right)\right)$ such that $c^{i}$ is a best response against $c^{-i}$ within $T_{k-1}^{i}$. The set $T_{\infty}=\lim _{k \rightarrow \infty} T_{k}$ is the set of trembling-hand perfect rationalizable strategy profiles of the game $\mathcal{G}$.

At each step of the iteration, a strategy $c^{i}$ of player $i$ has to be a best response against some conjecture $c^{-i} \in \operatorname{int}\left(\operatorname{ch}\left(T_{k-1}^{-i}\right)\right)$, the relative interior of the convex hull of the set $T_{k-1}^{-i}$. Such a conjecture is called a cautious conjecture. It follows that at each step of the iteration at least all weakly dominated strategies are deleted. The set of tremblinghand perfect rationalizable strategy profiles is shown to be non-empty in Herings and Vannetelbosch [10].

Theorem 3 The set of trembling-hand perfect rationalizable strategy profiles of the game $\mathcal{G}$ is non-empty.

Lemma 3 claims that any strategy which excludes the action $a_{1}^{i}$ is never a cautious best response, and can therefore not belong to $T_{1}^{i}$. In other words, it is never a best response for player $i$ to send a subset of actions to the matching device which does not contain the Pareto one, $a_{1}^{i}$. Moreover, one can show that submitting any strategy to the matching device that contains the Pareto action $a_{1}^{i}$ is individually rational.

Lemma 3 It holds that $s^{i} \notin T_{1}^{i}$ if and only if $a_{1}^{i} \notin s^{i}$.

Proof. We show first that $s^{i} \notin T_{1}^{i}$ if $a_{1}^{i} \notin s^{i}$. Consider any $s^{i}$ such that $a_{1}^{i} \notin s^{i}$. It follows as in the proof of Theorem 2 that $s^{i}$ is weakly dominated by $s^{i} \cup\left\{a_{1}^{i}\right\}$. 
We show next that $s^{i} \in T_{1}^{i}$ if $a_{1}^{i} \in s^{i}$. We observe first that if $s^{i}$ is the unique best response against a conjecture $c^{-i}$ (possibly degenerate), then it is also the unique best response against some cautious conjecture. More precisely, take any $s^{i} \in S^{i}$. If there exists $c^{-i}$ such (i) $c^{-i} \in \Delta\left(S^{-i}\right)$ and (ii) for all $\bar{s}^{i} \in S^{i}, \bar{s}^{i} \neq s^{i}, U^{i}\left(s^{i}, c^{-i}\right)>U^{i}\left(\bar{s}^{i}, c^{-i}\right)$, then, using a continuity argument, it follows that there exists $\widehat{c}^{-i}$ such that (iii) $\widehat{c}^{-i} \in \Delta^{0}\left(S^{-i}\right)$ and (iv) for all $\bar{s}^{i} \in S^{i}, \bar{s}^{i} \neq s^{i}, U^{i}\left(s^{i}, \widehat{c}^{-i}\right)>U^{i}\left(\bar{s}^{i}, \widehat{c}^{-i}\right)$.

Consider any $s^{i}$ such that $a_{1}^{i} \in s^{i}$. For $j \neq i$, let $c^{j}$ be a non-degenerate probability distribution on $\left\{a_{k}^{j}\right\}$, for $a_{k}^{i} \in s^{i}$, and $\left\{a_{1}^{j}, a_{k}^{j}\right\}$, for $a_{k}^{i} \notin s^{i}$. When all players $j$ play according to $c^{j}$, then there is only positive probability on intersections $\cap_{j \in N \backslash\{i\}} s^{j}$ of the form $\emptyset, a_{k}$ for $a_{k}^{i} \in s^{i}$, or $\left\{a_{1}, a_{k}\right\}$ for $a_{k} \notin s^{i}$. Notice that the play of $s^{i}$ results in the highest payoff possible, irrespective of the $\cap_{j \in N \backslash\{i\}} s^{j}$ that results from the play of $i$ 's opponents. The play of any proper subset of $s^{i}$ results in a strictly lower payoff when matched against $\left\{a_{k}\right\}$ for some $a_{k}^{i} \in s^{i}$ not in the proper subset. The play of a set of actions that contains an action $a_{k}$ not in $s^{i}$ results in a strictly lower payoff when matched against $\left\{a_{1}, a_{k}\right\}$. It follows that $s^{i}$ is the unique best response against the conjecture $c^{-i}$, and by the argument given above, it is the unique best response against some cautious conjecture. It follows that $s^{i} \in T_{1}^{i}$.

We can use Lemma 3 to show the following main result.

Theorem 4 It holds that $T_{2}^{i}=T_{\infty}^{i}=\left\{\left\{a_{1}^{i}\right\}\right\}, i \in N$.

Proof. From Lemma 3 we know that any $s^{j} \in T_{1}^{j}$ contains the action $a_{1}^{j}$. Then, irrespective of the choice of $s^{j} \in T_{1}^{j}, j \in N \backslash\{i\}$, the play of $s^{i}=\left\{a_{1}^{i}\right\}$ gives to player $i$ a utility $U^{i}\left(\left\{a_{1}^{i}\right\}, s^{-i}\right)=u^{i}\left(a_{1}^{1}, \ldots, a_{1}^{n}\right)$. Consider any $s^{i} \in T_{1}^{i}$ such that $s^{i} \neq\left\{a_{1}^{i}\right\}$. Obviously, $U^{i}\left(s^{i}, s^{-i}\right) \leq u^{i}\left(a_{1}^{1}, \ldots, a_{1}^{n}\right)$, for all $s^{-i} \in \prod_{j \in N \backslash\{i\}} T_{1}^{j}$. If $s^{j}=s^{i}, j \in N \backslash\{i\}$, then $U^{i}\left(s^{i}, s^{-i}\right)<u^{i}\left(a_{1}^{1}, \ldots, a_{1}^{n}\right)$. It follows that for any conjecture $c^{-i} \in \operatorname{int}\left(\operatorname{ch}\left(T_{1}^{-i}\right)\right)$, $U^{i}\left(s^{i}, c^{-i}\right)<u^{i}\left(a_{1}^{1}, \ldots, a_{1}^{n}\right)$. We have shown that $T_{2}^{i}=\left\{\left\{a_{1}^{i}\right\}\right\}$. It follows immediately from Theorem 3 that $T_{\infty}^{i}=\left\{\left\{a_{1}^{i}\right\}\right\}$.

To illustrate our results we consider the $3 \times 3$ pure coordination game depicted in Figure 3. Once we introduce fuzzy play and the simple matching device, we obtain a new game whose matrix payoffs are given by Figure 4 where $3>x>2,2>y>1,3>z>1$, $3>w>1$ and $w>y$. Obviously, the strategies of player $i$ that do not include the action $a_{1}$ are weakly dominated, and hence do not belong to $T_{1}^{i}$. Indeed, the strategies $\left\{a_{2}\right\},\left\{a_{3}\right\}$, $\left\{a_{2}, a_{3}\right\}$ are weakly dominated (and are never cautious best responses) by the strategies $\left\{a_{1}, a_{2}\right\},\left\{a_{1}, a_{3}\right\},\left\{a_{1}, a_{2}, a_{3}\right\}$. At the first round we eliminate all the strategies that do not include the action $a_{1}$. At the second round, both players know that their opponent 


\begin{tabular}{c|c|c|c|}
\multicolumn{1}{c}{$a_{1}^{2}$} & \multicolumn{1}{c}{$a_{2}^{2}$} & $a_{3}^{2}$ \\
\cline { 2 - 4 }$a_{1}^{1}$ & 3,3 & 0,0 & 0,0 \\
\cline { 2 - 4 }$a_{2}^{1}$ & 0,0 & 2,2 & 0,0 \\
\cline { 2 - 4 }$a_{3}^{1}$ & 0,0 & 0,0 & 1,1 \\
\cline { 2 - 4 } & & & \\
\cline { 2 - 4 } & &
\end{tabular}

Figure 3: A $3 \times 3$ coordination game

will never use such strategies. Since both players are cautious, their conjectures have to give positive weight to $\left\{a_{1}\right\},\left\{a_{1}, a_{2}\right\},\left\{a_{1}, a_{3}\right\}$ and $\left\{a_{1}, a_{2}, a_{3}\right\}$ of their opponent. As a consequence each player has a unique cautious best response, which is the strategy $\left\{a_{1}\right\}$. Indeed, this strategy will guarantee a payoff of 3 while any other strategy gives a payoff of at most 3 and a payoff strictly less than 3 against some strategies within the support of the conjecture. So, each player has a unique trembling-hand perfect rationalizable strategy, which consists of sending only the action $a_{1}$ to the device and which allows the players to coordinate perfectly on the Pareto-optimal outcome.

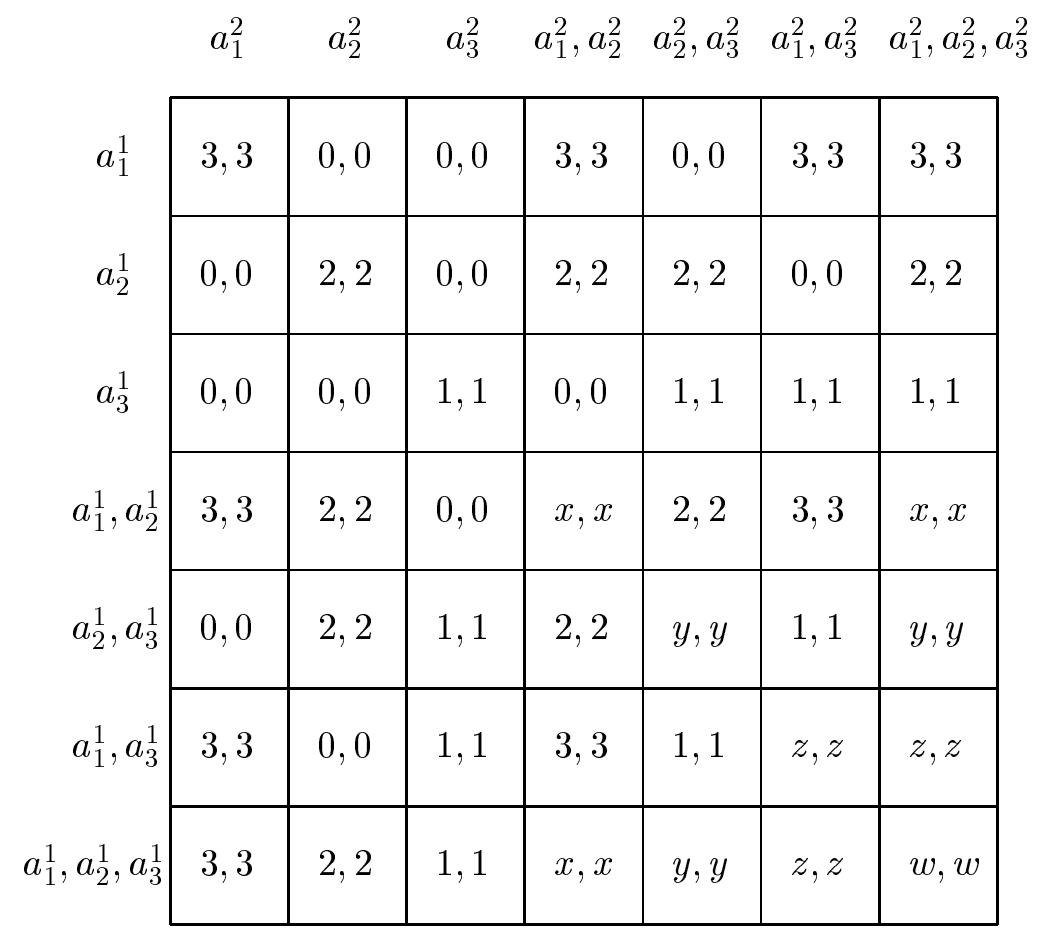

Figure 4: Fuzzy play in the $3 \times 3$ coordination game 


\section{Conclusion}

We have revisited n-player pure coordination games with Pareto-ranked Nash equilibria. The novelties that we have introduced are fuzzy play and a matching device. Each player does not choose which pure strategy to play, but instead chooses a nonempty subset of his strategy set that he submits to the matching device. The matching device we have considered is a very simple one. It only selects a match if possible, and it selects randomly some strategy belonging to the strategy set sent by each player otherwise. That is, it does not impose that the best alternatives are matched. We have applied the concepts of perfect Nash equilibrium and of trembling-hand perfect rationalizability to the resulting situation. It has been shown that all players coordinate directly on the Pareto optimal outcome. As a consequence, the players do neither use the possibility of fuzzy play, nor do they use the matching device. Both concepts lead to the conclusion that the mere possibility of fuzzy play and the mere availability of a simple matching device is sufficient for direct coordination on the Pareto optimal outcome.

\section{References}

[1] Bernheim, D., Rationalizable Strategic Behavior, Econometrica 52 (1984), 1007-1028.

[2] Bryant, J., A Simple Rational Expectation Keynes-Type Model, Quarterly Journal of Economics 97 (1983), 525-529.

[3] Carlsson, H. and E. van Damme, Global Games and Equilibrium Selection, Econometrica 61 (1993), 989-1018.

[4] Cooper, R.W., Coordination Games : Complementarities and Macroeconomics, Cambridge University Press 1999.

[5] Cooper, R.W., D.V. Dejong, R. Forsythe and T.W. Ross, Communication in Coordination Games, Quarterly Journal of Economics 107 (1992), 739-771.

[6] Cooper, R.W. and A. John, Coordinating Coordination Failures in Keynesian Models, Quarterly Journal of Economics 103 (1988), 441-463.

[7] Farrel, J., Cheap Talk, Coordination and Entry, Rand Journal of Economics 18 (1987), 34-39.

[8] Farrel, J., Communication, Coordination and Nash Equilibrium, Economics Letters 27 (1988), 209-214. 
[9] Harsanyi, J. and R. Selten, A General Theory of Equilibrium Selection in Games, MIT Press 1988.

[10] Herings, J.J. and V.J. Vannetelbosch, Refinements of Rationalizability for NormalForm Games, International Journal of Game Theory 28 (1999), 53-68.

[11] Kandori, M., G. Mailath and R. Rob, Learning, Mutation and Long Run Equilibria in Games, Econometrica 61 (1993), 29-56.

[12] Kohlberg, E. and J.-F. Mertens, On the Strategic Stability of Equilibria, Econometrica 54 (1986), 1003-1037.

[13] Ochs, J., Coordination Problems, in J.H. Kager and A.E. Roth (eds.), The Handbook of Experimental Economics, Princeton: Princeton University Press,195-251.

[14] Pearce, D.G., Rationalizable Strategic Behavior and the Problem of Perfection, Econometrica 52 (1984), 1029-1050.

[15] Rabin, M., A Model of Pre-Game Communication, Journal of Economic Theory 63 (1994), 370-391.

[16] Selten, R., Re-examination of the Perfectness Concept for Equilibrium Points in Extensive Games, International Journal of Game Theory 4 (1975), 25-55.

[17] Van Damme, E., Stability and Perfection of Nash Equilibria, Springer-Verlag 1991. 